\title{
Non-consensual disclosure of infectious drug-resistant tuberculosis status in the occupational context: Health workers stuck between a rock and a hard place
}

\author{
C Nnaji, ${ }^{1}$ MBBS, MPH; S Adams, ${ }^{2}$ MB ChB, MFamMed, DOH, MMed (Occ Med), FCPHM (Occ Med); \\ L London, ${ }^{1}$ MB ChB, BSc Hons (Epid), DOH, MMed (Public Health), MD, FCPHM \\ ${ }^{1}$ Division of Public Health Medicine, School of Public Health and Family Medicine, University of Cape Town, South Africa \\ ${ }^{2}$ Division of Occupational Medicine, School of Public Health and Family Medicine, University of Cape Town, South Africa
}

Corresponding author: C Nnaji (nnjchu001@myuct.ac.za)

\begin{abstract}
Background. The burden of drug-resistant tuberculosis (DR-TB) remains high in South Africa (SA), despite ongoing control efforts. DR-TB patients who are infectious and continue to work pose a substantial risk of spreading the disease at the workplace. When such patients refuse or interrupt treatment, and are also unwilling to disclose their status at work, they pose an infectious risk in the workplace, creating a conflict between public health good and individual human rights. Should health workers breach confidentiality and disclose patients' DR-TB status, or take no action while patients pose transmission risks in occupational settings? Non-consensual disclosure of the infectious DR-TB status of such patients is an intervention intended to address this occupational health risk.

Objectives. To provide professional and ethical guidance for health workers in dealing with non-consensual disclosure of the DR-TB status of patients who are unwilling to disclose, continue to go to work and remain infectious.

Methods. A comprehensive literature search was conducted to draw on evidence relating to public health best practices and human rights normative standards. We used the findings, along with guidance from DR-TB programme managers, clinicians, occupational health physicians and human rights lawyers to develop an occupational health protocol for disclosure.

Results. This protocol establishes the normative, ethical and legal framework for dealing with the complexities of non-consensual disclosure, and provides a set of practical standard operative procedures for health workers in the SA setting. It also provides a legal safeguard to protect health workers from potential litigation that may result from such duty.

Conclusion. Non-consensual disclosure to address the spread of DR-TB in occupational settings should be based on professional, ethical and legally sound guidance for health workers.
\end{abstract}

S Afr J Bioethics Law 2020;13(1):34-42. https://doi.org/10.7196/SAJBL.2020.v13i1.686

Drug-resistant tuberculosis (DR-TB) is of enormous public health concern in South Africa (SA), as a leading cause of morbidity, disability and premature death in the country. ${ }^{[1]}$ With less than $1 \%$ of the world's population, SA accounts for $15 \%$ of the global DR-TB burden. ${ }^{[2]}$ The national burden remains high despite ongoing control efforts. ${ }^{[1,3,4]}$ This is partly a result of high treatment interruption and loss to followup rates, with $30 \%$ of patients who start treatment lost to follow-up, and $67 \%$ retention at 18 months. ${ }^{[1,3]}$ It has been recognised that DR-TB patients' reasons for interrupting treatment may be personal, social or structural. ${ }^{[1,4]}$ Personal reasons include patients' perceptions of treatment, hospital admission or regular clinic attendance as intrusions into their work schedule, and they may, therefore, interrupt treatment for the reason of returning to work. ${ }^{[4]}$

DR-TB poses a serious risk of transmission in the workplace, especially in high-risk settings such as healthcare and mining. ${ }^{[5,6]}$ Airborne diseases such as TB can be transmitted to contacts who are often unaware of such risk and may be unable to take precautions to protect themselves. ${ }^{[7]}$ Studies have shown that substantial TB transmission occurs outside of household settings, such as in public transport and shared workspaces. ${ }^{[5,6,8,9]}$
The question as to whether a health worker has a duty to divulge confidential information to protect the public health interest without the patient's consent continues to be a subject of debate globally. ${ }^{[7,10]}$ As a result, there is no clear consensus on non-consensual disclosure, with very little evidence on enabling policies and practices contained in World Health Organization (WHO) recommendations, treatment and ethics guidelines or judicial rulings from notable court cases. The WHO's guidance on the ethics of TB prevention and control recognises that the health of contacts of people with infectious TB is seriously threatened, especially if they are infected with a drugresistant strain. It therefore recommends that health workers should balance duties to their patients with an obligation to protect the lives of others at risk, and that non-consensual disclosure should be considered when all reasonable efforts to engage the patient's co-operation have failed. ${ }^{[1]}$

In the USA, the duty to disclose was first legally defined in the 1976 landmark Tarasoff ruling by the Supreme Court of California, in which it was held that 'the privilege [of confidentiality] ends where the public peril begins.' Under this ruling, physicians have the duty to warn or protect third parties from patients with severe medical conditions. ${ }^{[12]}$ 
In Canada, the confidentiality of patient information is protected by statute except in certain circumstances, when a physician's duty to the public outweighs the principle of confidentiality. In such cases, Canadian law permits the physician to provide information about a patient without his or her consent to protect society. ${ }^{[12]}$ In a notable court case (Smith v Jones), the Canadian Supreme Court established three criteria that must be present before non-consensual disclosure can be deemed appropriate: (i) there must be a clear risk to an identifiable third party (person or group of people); (ii) there must be a risk of serious health or bodily harm or death to the third party; and (iii) the danger must be imminent. ${ }^{[13]}$

Some medical regulatory bodies have also taken clear-cut positions on the issue. The UK General Medical Council in 2004 held that disclosing personal information about a patient without consent may be justified in the public interest if failure to do so may endanger public health safety or expose others to a serious risk of harm. ${ }^{[14]}$ Similarly, the American Psychiatric Association's guidelines provide that non-consensual disclosure to protect third parties at risk of infection through the behaviour of an HIV-positive patient is ethically permissible if the psychiatrist has exhausted efforts to work with the patient to terminate such behaviour that places others at risk. ${ }^{[10]}$

The complex question as to whether the constitutional right to freedom and security of the person and/or privacy may be limited where public health interest is paramount has been the subject of a previous case law in SA (Minister of Health for Western Cape v Goliath and Others). ${ }^{[15]}$ In that case, the respondents had all been diagnosed with extensively drug-resistant TB (XDR-TB). Because they were contagious and had failed to comply with the voluntary treatment regimen prescribed for them, the Minister of Health applied for an order compelling the respondents to be detained in a specialist TB hospital to receive treatment. The court considered various factors, including: the respondents' rights in terms of section 12 of the Constitution, ${ }^{[16]}$ including their rights to freedom of movement; that the respondents were capable of spreading the disease, but had failed to adhere to the voluntary treatment; and the toxicity and associated side-effects of the drugs necessary to treat XDR-TB. Other considerations included the Minister of Health's duty to prevent and control the spread of communicable diseases in terms of section 7(1) (d) of the National Health Act No. 61 of $2003(\mathrm{NHA}){ }^{[17]}$ Following its evaluation of these considerations, the court ruled that the detention and treatment of the respondents, although a breach of their section 12 rights, were both necessary and mandated by section $7(1)(d)$ of the NHA to protect public health interest. While the judgment is not directly related to the context of non-consensual disclosure of DR-TB status, and did not adequately traverse the requirements outlined in section 36 for limiting human rights, it illustrates the applicable Constitutional principle that public health interest may, in specific circumstances, take preference over an individual's rights to freedom and security of the person, privacy and bodily integrity. ${ }^{[15]}$

At the same time, under section 14 of the NHA, healthcare professionals in SA have a duty to protect patients' rights to confidentiality, and must not disclose any information relating to patient's health status without their informed consent. However, section 90 of the NHA defines the circumstances in which this right can be limited, including where non-disclosure of the information represents a serious threat to public health (Table 1). Under the ethical guidelines of the Health Professions Council of SA, healthcare practitioners have the duty to respect patients' right to autonomy, informed consent and confidentiality, including the right to refuse treatment. However, section 8.2.4.1 of booklet $10^{[18]}$ of the guidelines similarly prescribes that, in situations where healthcare practitioners have considered all available means of obtaining consent, but are satisfied that it is not practicable to do so, personal information may be disclosed where the public benefit of disclosure outweighs the patient's interest in keeping the information confidential (Table 1).

In the context of occupational health and safety, scheduled disclosure of the DR-TB status of workers who are refusing, interrupting or failing DR-TB treatment raises many ethical and human rights concerns. It creates a dilemma between the rights of the individual and the duties of the health system to control infectious diseases for the public good. The relevant regulatory framework incorporating human rights, public health acts and occupational health statutes are summarised in Table 1.

TB is an airborne disease that can be transmitted to contacts who may be unaware of such risk, and unable to take precautions to protect themselves. ${ }^{[5,6]}$ Effective tracking of treatment defaulters to ensure return to treatment can help reduce the DR-TB burden by $30 \%$, using second-line regimens. ${ }^{[2]}$ There is therefore a need to explore strategies of optimising treatment adherence and reducing infectiousness and transmission.

Disclosure of the DR-TB status of patients refusing or interrupting treatment to their employers or managers without their consent is an intervention that could support infection control measures in workplace settings, protect workers and the public from DR-TB and reduce the stigma associated with this condition. However, such disclosure can bring with it moral, ethical and legal concerns, particularly where patients are reluctant and/or refuse to disclose. There is therefore a need for a standard operating procedure consistent with normative and legal frameworks that balance the public health purpose of such workplace disclosure with its human rights implications. Furthermore, this protocol is necessitated in view of the high burden of HIV/AIDS in SA and the country's workforce, making a substantial proportion of the workforce who are HIVinfected vulnerable to opportunistic TB infection. The protocol should be consistent with the WHO's recommendation that duty to third parties may justify disclosure of patients' TB status without their consent, and that public health authorities and TB programmes should develop clear policies, standards and procedures governing such disclosure. ${ }^{[11]}$ The obligation to protect potential victims of DR-TB transmission in high-risk settings such as workplaces has become an issue that must be dealt with in routine clinical practice and public health systems at large. ${ }^{[30]}$

The present protocol was therefore developed to provide professional and ethical guidance for health workers in dealing with non-consensual disclosure of the DR-TB status of patients.

\section{Methodology}

A comprehensive search of the literature was conducted to draw on evidence relating to public health and human rights best practices and normative standards. Inputs were sought from consultative forums with clinicians, occupational health physicians, provincial DR-TB programme managers, municipal environmental health practitioners and human rights lawyers. Additional inputs were also received from provincial DR-TB review committee members. 
Table 1. Summary of relevant human rights, public health acts and occupational health statutes (adapted from Adams et al. ${ }^{[19]}$ )

\begin{tabular}{ll}
\hline Act/law & Relevant section \\
\hline International Covenant & Right to health (article 12 and \\
on Economic, Social and & general comment 14) \\
Cultural Rights ${ }^{[2]}$ &
\end{tabular}
Summary of provision Enforcing agency

Cultural Rights ${ }^{[20]}$

International Covenant on Civil and Political Rights ${ }^{[21]}$

\section{SA Constitution ${ }^{[16]}$}

Right to dignity (s10); right to privacy (s14); right to freedom of trade, occupation and profession (s22); right to an environment that is not harmful to health or wellbeing (s24); conditions under which limitation of rights can be justified (s36)

National Health Act No. 61 Right to privacy and of 2003 (NHA) ${ }^{[17]}$

Occupational Health and Safety Act No. 85 of $1993^{[2]}$

Basic Conditions of Sick leave (s22); proof of Employment Act No. 75 of incapacity (s23) $1997^{[23]}$

The Labour Relations Act No. 66 of 1995 (as amended in 2014) $)^{[24]}$ Compensation of Occupational Injuries and Diseases Act No. 130 of $1993^{[25]}$ from work (s191) diseases (s65)
Health and safety duties of employers to their employees (s8-10); health and safety duties of employees to their employers and co-workers (s14) confidentiality (s14); health workers' obligations to notify medical conditions that are deemed notifiable by law (s90)
By being party to the covenant, the South African

(SA) government assumes obligations and duty to respect, protect and fulfil the right of persons to the enjoyment of the highest attainable standard of physical and mental health. This obligation includes protection from the risk of preventable disease transmission.

No one shall be subjected to arbitrary or unlawful interference with his privacy, family, home or correspondence, nor to unlawful attacks on his honour and reputation.

The state, institutions and individuals have the collective responsibility to respect, protect and fulfil the rights in the Bill of Rights, taking into account the nature of the right and the nature of any duty imposed by the right; rights may be limited under certain condition, and such limitation is justifiable if its purpose is to protect others' rights, or in the public interest and in the absence of less restrictive means to achieve the purpose.

Healthcare professionals have the duty to protect patients' rights to confidentiality, and must not disclose any information relating to the patient's health status without their informed consent, unless a court order or any law (such as $s 90$, which provides for notification) requires that disclosure, or non-disclosure, of the information represents a serious threat to public health.

Both employers and employees have obligations Department of Labour to ensure the protection of occupational health and safety. Every employer is required to provide and maintain, as far as is reasonably practicable, a working environment that is safe and without risk to the health and safety of employees, while also requiring employees to take reasonable care for the health and safety of themselves and of other persons who may be affected by their acts or omissions; employers must also do risk assessment and implement medical monitoring of workers who need monitoring.

During every sick leave cycle, an employee is entitled to an amount of paid sick leave. For this, the employee must produce a medical certificate stating that the employee was unable to work for the duration of the absence on account of sickness or injury.

Protection from unfair dismissal An employee who feels unfairly dismissed by the employer may elect to refer the dispute either to arbitration or to the labour court.

Compensation for occupational Provides for medical cover and compensation
Nations High Commissioner for Human Rights

Office of the United Nations High Commissioner for Human Rights

Department of Justice

Department of Health

Department of Labour

Department of Labour

Department of Labour
Office of the United of occupational injuries or diseases arising from workplace exposures. It also allows for wage replacement if disabled by disease and unable to work, such as for occupationally acquired TB. 
Table 1. (continued) Summary of relevant human rights, public health acts and occupational health statutes (adapted from Adams et al. $\left.{ }^{[19]}\right)$

\begin{tabular}{|c|c|c|c|}
\hline Act/law & Relevant section & Summary of provision & Enforcing agency \\
\hline $\begin{array}{l}\text { Unemployment Insurance } \\
\text { Act No. } 63 \text { of } 2001^{[26]}\end{array}$ & Part C (illness benefits) s19- 23 & $\begin{array}{l}\text { Provides for the payment of unemployment } \\
\text { benefits to employees when they become } \\
\text { unemployed and unable to work due to } \\
\text { conditions such as illnesses. }\end{array}$ & Department of Labour \\
\hline $\begin{array}{l}\text { Social Assistance Act No. } \\
13 \text { of } 2004^{[27]}\end{array}$ & $\begin{array}{l}\text { Eligibility for disability grant } \\
\text { (s3) }\end{array}$ & $\begin{array}{l}\text { A person is eligible for a disability grant if he or } \\
\text { she is disabled and does not, without good reason, } \\
\text { refuse to undergo the necessary medical or other } \\
\text { treatment recommended by a medical officer. }\end{array}$ & SA Social Security Agency \\
\hline $\begin{array}{l}\text { City of Cape Town } \\
\text { Environmental Health } \\
\text { By-law }\end{array}$ & $\begin{array}{l}\text { Trade and accommodation } \\
\text { establishment regulation ( } \mathrm{s} 28 \text { ) }\end{array}$ & $\begin{array}{l}\text { The owner of a business or employers must not } \\
\text { knowingly cause or permit any person suffering } \\
\text { from a communicable disease to be employed in } \\
\text { or on the premises unless (s)he is in possession of } \\
\text { a medical certificate to the effect that such person } \\
\text { is fit to continue his or her employment. }\end{array}$ & $\begin{array}{l}\text { City of Cape Town } \\
\text { Environmental Health Services }\end{array}$ \\
\hline $\begin{array}{l}\text { Guidelines for Good } \\
\text { Practice in the Health Care } \\
\text { Professions }{ }^{[18]}\end{array}$ & $\begin{array}{l}\text { Ethical considerations in } \\
\text { seeking informed consent } \\
\text { (booklet 9); } \\
\text { Protecting patient's } \\
\text { confidentiality (booklet 10) }\end{array}$ & $\begin{array}{l}\text { Healthcare practitioners must respect the } \\
\text { patient's right to autonomy, informed consent } \\
\text { and confidentiality, including the right to refuse } \\
\text { treatment. However, practitioners also have } \\
\text { certain legal obligations as stipulated by the NHA. } \\
\text { Section } 8.2 .4 .1 \text { of booklet } 10 \text { describes cases in } \\
\text { which healthcare practitioners have considered all } \\
\text { the available means of obtaining consent, but are } \\
\text { satisfied that it is not practicable to do so, personal } \\
\text { information may be disclosed in the public } \\
\text { interest where the benefits to an individual or to } \\
\text { society of the disclosure outweigh the public and } \\
\text { the patient's interest in keeping the information } \\
\text { confidential. }\end{array}$ & $\begin{array}{l}\text { Health Professions Council } \\
\text { of SA }\end{array}$ \\
\hline
\end{tabular}

The following pertinent questions and key considerations guided the protocol development. Under what circumstances can nonconsensual disclosure be justifiable? How much of a serious public health threat is DR-TB in the workplace? Which of the rights enshrined in the SA Bill of Rights, Constitution and NHA can pose legal dilemmas to non-consensual disclosure? Which of those rights can be limited within reasonable and justifiable considerations? How does the protocol navigate the implementation challenges in the informal and private sectors, where occupational health and safety considerations are often limited or absent? Are there extant provincial occupational and environmental health laws that can lend legal support to the protocol? Are there existing professional statutes, rules and regulations that can provide some measure of normative standards? Are there national and global best practices that can be leveraged? Other questions that arose were: what social security benefits or labour law statutes can be explored to encourage patients' early return to treatment? What collaborative opportunities can be explored, such as amendment of the Road Traffic Act to ensure that professional drivers are DR-TB free before licensure?

This protocol was structured in line with the End TB strategy of the $\mathrm{WHO}$, and is guided by the following principles:

(i) The non-consensual disclosure of the patient's health status to a third party interferes with their rights to privacy and confidentiality, both of which are a cornerstone of the healthcare worker-patient relationship. (ii) Third parties such as workplace contacts also have rights, which government has the obligation to protect for the public health good.

(iii) Patients' right to confidentiality may be limited, but only if such limitation is done either in line with section 36 of the SA Constitution, or Siracusa Principles. ${ }^{[31]}$

(iv) Recognising that patients are part of their larger communities enables the identification of public health risks and approaches to mitigating such risks.

It lays down normative and legal support, drawn from a broad range of global, national and province-level evidence, for dealing with the ethical complexities of non-consensual disclosure in occupational settings. This protocol proposes an integrated, stepwise incident management and initial risk assessment algorithm adapted from models proposed by Appelbaum ${ }^{[30]}$ and Chaimowitz. ${ }^{[32]}$

\section{Results \\ Incident management process}

An incident of DR-TB treatment outcome may comprise one of the following scenarios: (i) treatment interruption; (ii) treatment failure; (iii) on treatment but still infectious; or (iv) refusal to initiate treatment. The key steps in the incident management process are highlighted below and schematically described in flow charts (Figs 1 and 2). 


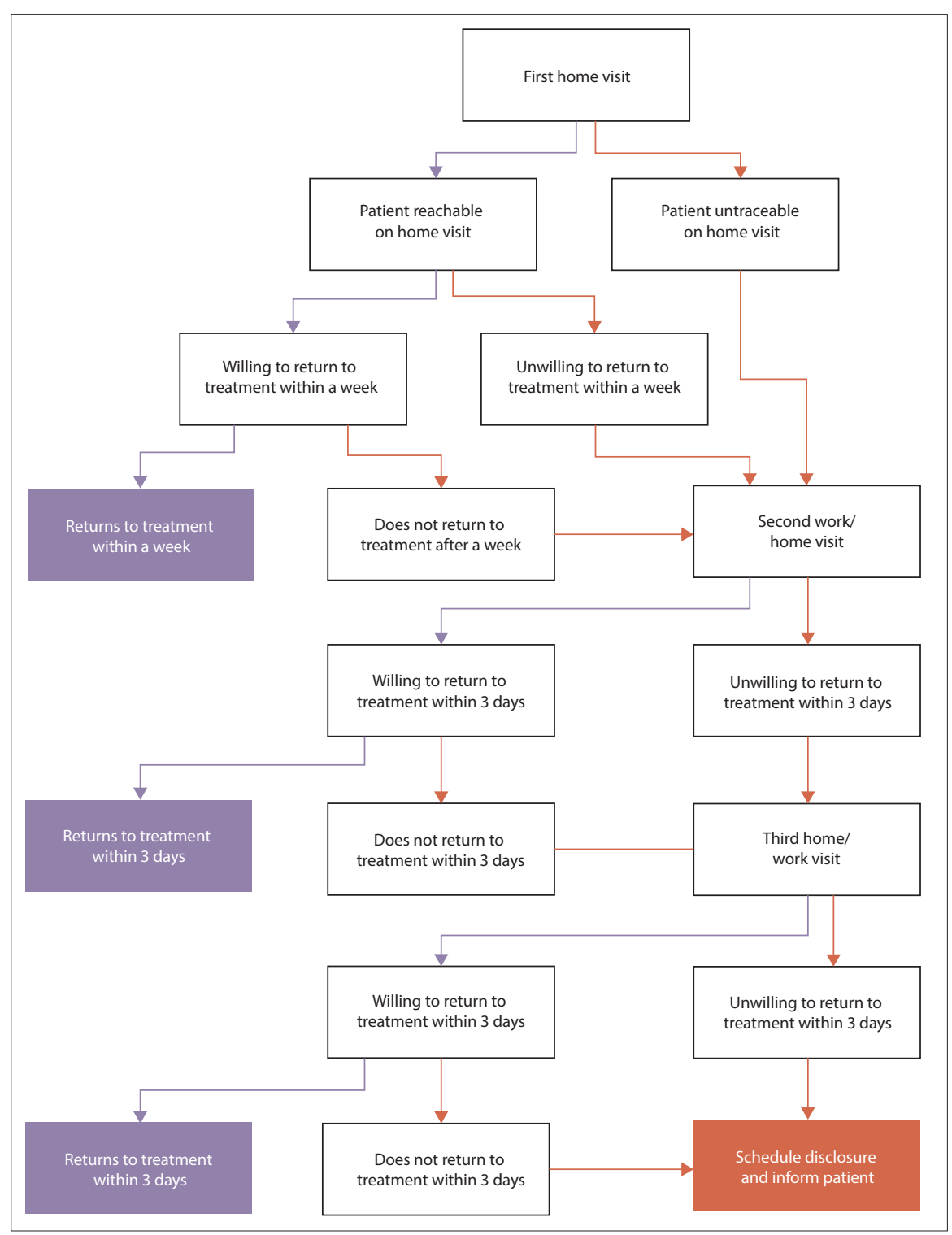

Fig. 1. Incident management for patients interrupting treatment and still going to work.

(i) Following the establishment of an incident, the treating physician should notify the health facility's DRTB professional nurse, or a similarly designated officer.

(ii) Upon notification, the DR-TB professional nurse, or other designated officer, should, within 3 working days, arrange for a clinic counselling session (in the case of patients who are currently on treatment but remain infectious), or designate social workers to conduct a home visit (in the case of treatment interruption or those refusing to initiate treatment after the DR-TB diagnosis).

(iii) There is a need for careful assessment of each incident, on a case-by- case basis, of current employment status and whether the patient has already disclosed their DR-TB status at the workplace. This is necessary to avoid unwarranted disclosure (e.g. in situations where patients are neither currently going to work nor employed, in which case domestic and occupational infection control strategies can be instituted with adequate communication and counselling of patients and household members).

(iv) Any successful contact of patients or their family members/next of kin, either telephonically and/or through a home visit, is a vital opportunity to ascertain their current /employment status. (v) If, after the third home visit, the patient remains untraceable and it is obvious that family members and home contacts do not know his or her whereabouts, the patient should be considered as lost to follow-up.

(vi) However, if at any home visit attempt the patient is untraceable and it is obvious that he or she is deliberately refusing to see or evading the social workers, such home visit attempt should be deemed unsuccessful, as per the incident management algorithm.

(vi) To encourage early return to treatment and care, patients should be made aware of the possibility of accessing social security benefits (a disability grant or unemployment insurance funds, or both), where patients are eligible. These benefits will also lessen the economic implication of loss of income due to sick leave taken on medical grounds, until they achieve at least one negative sputum culture result.

(viii) To encourage disclosure by self in patients still on treatment but who pose a transmission risk, efforts should be made to secure access to social security benefits to allow patients sick leave. Where a patient continues to work after disclosure, there is a need to ensure appropriate infection prevention and control measures at the workplace.

(ix) Documentation of all clinic and home visit counselling and persuasion attempts, with their outcomes, in a tracking log book is recommended.

$(x)$ For patients who are willing to return to treatment and care after a home visit, non-consensual disclosure is usually neither necessary nor appropriate. As far as possible, the treating clinician should grant patients sick leave until they achieve a first negative sputum culture while on resumed treatment.

$(x i)$ The processes of application for social benefits such as a disability grant and/or UIF benefits require medical justification, which should be supported and motivated for by the treating physician.

(xii) For employees in private sector employment, the possibility of accessing temporary incapacity benefits from private insurance 


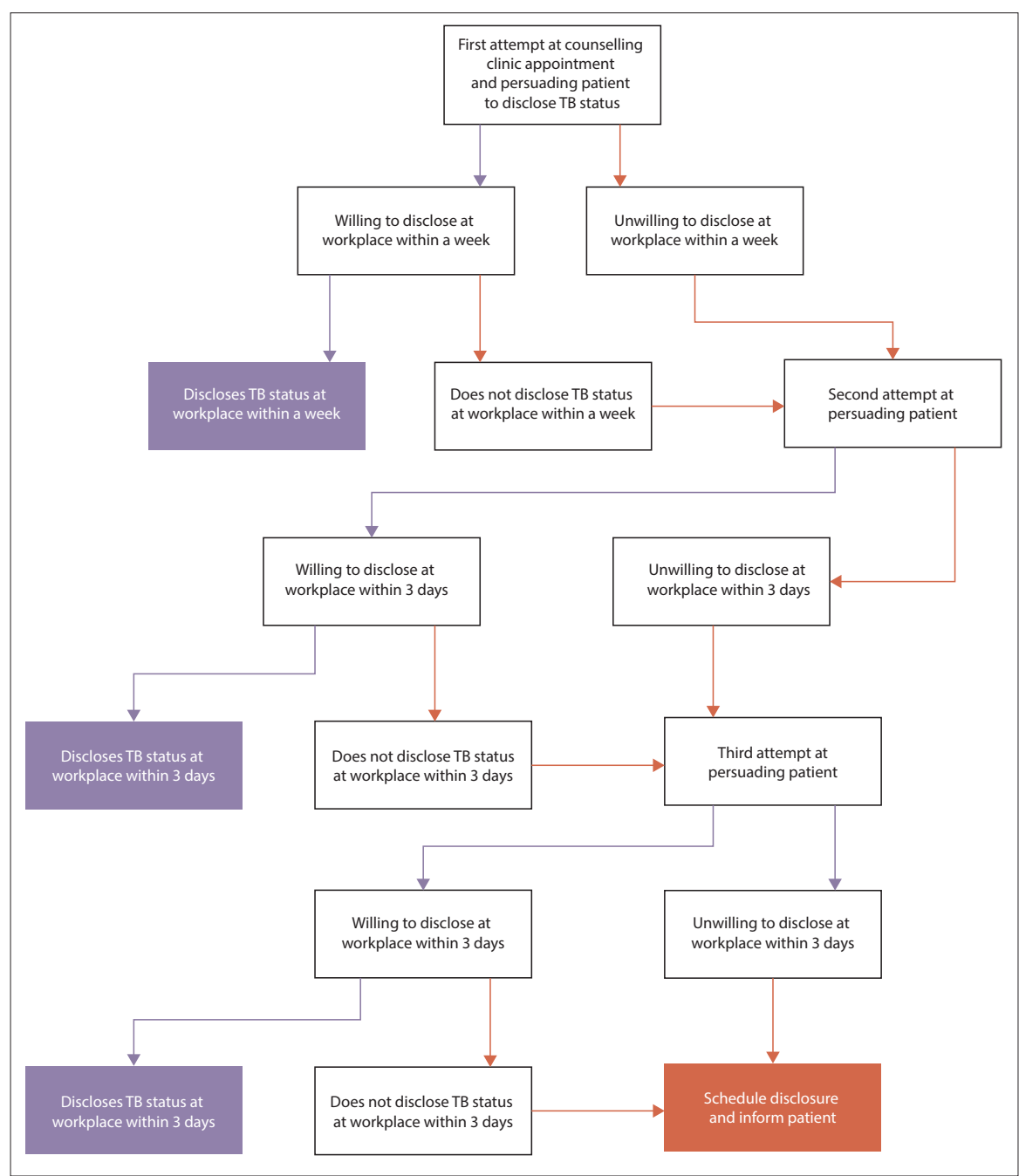

Fig. 2. Incident management for patients on treatment, still infectious and still going to work. ( $T B=$ tuberculosis).

benefits can be explored. Contracted staff and those without private health insurance benefits should be assisted to access benefits via the Department of Labour's UIF.

\section{Non-consensual disclosure}

Non-consensual disclosure becomes inevitable with persistent unwillingness to return to treatment despite sufficient attempts to get the patient backon treatment. Non-consensual disclosure should be done as respectfully and discreetly as possible by members of the healthcare team, and only information that is vital to protect the public from harm should be disclosed. Disclosure should be made only to those who need to know. Such persons may include employers, human resource managers, occupational health officers or other designated staff responsible for employee health and safety management. Patients should be provided
A stepwise approach to implementing non-consensual disclosure is outlined in Table 2.

\section{Situations where disclosure can be deemed inevitable}

Disclosure should be considered inevitable in the following situations:

(i) Interrupted treatment, and currently going to work but unwilling to return to care after exhausting all persuasive steps of the incident management algorithm (at least three home visits or clinic persuasive attempts).

(ii) Refusing to initiate treatment, and currently going to work but still unwilling to initiate treatment after exhausting all persuasive steps of the incident management algorithm (at least three home visits or clinic persuasive attempts).

(iii) Failed treatment, currently going to work but unwilling to self-disclose DR-TB status at work after exhausting all persuasive steps of the incident management algorithm.

(iv) On treatment but still infectious, and currently going to work but unwilling to self-disclose DR-TB status at work after exhausting all persuasive steps of the incident management algorithm.

\section{Resources required}

Due consideration must be given to the provision of necessary resources and capacity to implement this protocol (Table 3), and a framework for monitoring and evaluation is essential (Table 4).

(i) Human resources: physicians, DR-TB professional nurses, social workers, environmental health officers, TB counsellors, community health workers and health records personnel

(ii) Diagnostics: drug susceptibility testing tracking and results retrieval, National Health Laboratory Services database linkage and prompt response

(iii) Patient-tracking resources, monthly updated patient contact details, monthly occupational-status tracking register and incident management log book

(iv) Channels of collaboration between the Department of Health with other relevant authorities and stakeholders (Table 3). 
Table 2. Stepwise approach to implementing non-consensual disclosure

\begin{tabular}{|c|c|}
\hline Step 1 & $\begin{array}{l}\text { DR-TB professional nurse or any other designated officer in that capacity nominates disclosure team. The team should include a } \\
\text { clinician, an EHO and a social worker. }\end{array}$ \\
\hline Step 2 & $\begin{array}{l}\text { Disclosure team contacts workplace, identifies employer, manager or any other focal person, and proposes visit for occupational } \\
\text { purpose (patient's identity needs not be revealed at this stage). }\end{array}$ \\
\hline Step 3 & $\begin{array}{l}\text { Make visit as scheduled. Ascertain that patient is currently going to work. Once ascertained, the EHO discusses with workplace } \\
\text { contact person the purpose of visit. Assess the workplace for any existing occupational health policy, number of staff, infection } \\
\text { control measures and risks of occupational exposure and TB transmission at patient's occupational setting. }\end{array}$ \\
\hline Step 4 & Assess employer or manager's understanding of the purpose and goals of disclosure. \\
\hline Step 5 & Make disclosure. \\
\hline Step 6 & $\begin{array}{l}\text { Provide education to adequately provide relevant information to allay undue fear, apprehension and concerns, while mitigating } \\
\text { risks of stigma, discrimination and possible assault on patient. }\end{array}$ \\
\hline Step 7 & $\begin{array}{l}\text { Discuss with employer and explore possibilities of social security and unemployment benefits for patient while booked off work } \\
\text { following disclosure. }\end{array}$ \\
\hline Step 8 & Screening of workplace contacts, if indicated. \\
\hline Step 9 & $\begin{array}{l}\text { Monthly visits by the } \mathrm{EHO} \text {, in exceptional cases where } \mathrm{EHO} \text { deems transmission risk minimal enough to allow patient to continue } \\
\text { to work post disclosure, to monitor the impact of disclosure on patient and to ensure compliance with workplace infection } \\
\text { control measures. }\end{array}$ \\
\hline
\end{tabular}

$\mathrm{DR}-\mathrm{TB}=$ drug-resistant $\mathrm{TB} ; \mathrm{EHO}=$ environmental health officer.

Table 3. Resources required

\begin{tabular}{ll}
\hline Agency & Purpose \\
\hline South African Social Security Agency & Assist with access to social security opportunities for patients booked off \\
& work on medical grounds \\
Municipal and local government health services authorities & Establish contact with workplaces and evaluate risk \\
Department of Health legal department/committee & Advise clinician on legally complex cases \\
Transport authorities & $\begin{array}{l}\text { Deal with cases in which taxi drivers pose DR-TB transmission risks to } \\
\text { passengers } \\
\text { Department of Labour }\end{array}$ \\
& Ensure compliance with labour legislation, and protection for medically \\
& impaired employee
\end{tabular}

Table 4. Monitoring and record-keeping framework

\begin{tabular}{ll}
\hline Record-keeping & Frequ \\
\hline $\begin{array}{l}\text { Documentation of all attempts and outcomes of phone call, } \\
\text { home visit and clinic counselling/persuasion activities }\end{array}$ & $\begin{array}{l}\text { Followind } \\
\text { activity }\end{array}$ \\
$\begin{array}{l}\text { Post-disclosure monitoring of impact of disclosure on } \\
\text { patients who continue to work for identification of stigma, } \\
\text { discrimination and workplace adherence to infection } \\
\text { control measure }\end{array}$ & Monthy \\
$\begin{array}{l}\text { Tracking and validating current employment status of } \\
\text { patients on treatment }\end{array}$ & Monthy \\
$\begin{array}{l}\text { DR-TB = drug-resistant TB; EHO = environmental health officer. } \\
\end{array}$ & \\
Procedure for seeking redress on the grounds of \\
human rights abuses of this protocol
\end{tabular}

Consideration of human rights implications is a core element of public health policies and laws. ${ }^{\left[{ }^{[4]}\right.}$ Healthcare providers, as custodians of this protocol, therefore have the responsibility to ensure that they act in accordance with professional ethics and humaneness in the discharge of their duties, while ensuring minimal risk to the fundamental rights and freedoms of the patient. Like any other public health intervention, inadvertent violation of human rights can result from implementing this protocol. Should any undue violation of rights occur from the implementation of this protocol, however, this protocol includes the following procedure for channelling of complaints: it is proposed that the avenue for laying complaints and seeking redress be through existing health committees, or community tribunals, which will independently investigate reported cases and mediate in collaboration with the legal advisory team, including human rights lawyers.

\section{Discussion}

This protocol provides professional, legal and ethical guidance for health workers in dealing with the dilemma of non-consensual 
disclosure to limit the spread of DR-TB in occupational settings. The analysis of global and local bioethical and legal standards highlights the enormous challenge of balancing public health and human rights. We acknowledge that forced public health interventions such as non-consensual disclosure of DR-TB status, for the most part, are not desirable, but may be necessary in circumstances where such interventions are clearly in the public health interest and where alternatives are not feasible or effective. Nevertheless, it is possible to achieve this balance by incorporating human rights principles into policies that limit individual rights in the interests of the public good, and still meet ethical standards.

\section{Foreseeable implementation challenges}

(i) Challenges stem from the fact that a substantial proportion of DR-TB patients work in the informal sector, which means they are often unregistered and hard to reach. These include self-employed persons in informal occupational settings, taxi drivers, owners of outlets such as shebeens, baby daycare centres and hair salons.

(ii) Operationalisation can be limited by unavailable or incorrect phone and/or physical address contact details of patients.

(iii) An overburdened health workforce in short-staffed health facilities may also pose a challenge.

\section{Additional recommendations}

(i) To aid future tracing of patients, there is a need for proper documentation and tracking (at each clinic visit) of current patients' current contact details, including phone and residential addresses

(ii) To enable the determination of probable current employment status at any point in time while on treatment, there is a need for patients' employment status to be monitored monthly during clinic visits, and validated through a contactable next-of-kin.

(iii) Application of municipal by-laws and involvement of specialised health services for environmental health assessment of transmission risk at informal settings such as unregistered creches, hair salons and daycare facilities is needed.

(iv) There is a need for intensified counselling and continuous education of patients on the transmission risks of DR-TB.

(v) The National Transport Act should be amended to make the issue of a professional driving permit (PDP) contingent on the medical certification of the applicant as being free from infectious TB.

\section{Conclusion}

Addressing the serious problem of DR-TB in the occupational setting and non-disclosure by infectious TB patients may create an ethical dilemma of dual loyalty for health workers. ${ }^{[35]}$ While the limitation of an individual's rights may be a necessity to protect the public interest, including the prevention and control of communicable diseases, it is important that such a limitation is not undertaken in an arbitrary manner, or without regulation. It must be done in terms of a policy that is consistent with national and international human rights law governing the limitation of rights in the public interest. The present protocol aims to ameliorate that challenge by providing guidance that is based on a consideration of professional, ethical and legally sound principles that support non-consensual disclosure, and balance the public health goals of the intervention with its human rights implications.
Acknowledgements. We are grateful to advocates William Kerfoot and Geoff Budlender for offering the valuable constitutional and legal insights that guided this protocol. Our gratitude also goes to Yulene Kock of the Western Cape Provincial DR-TB Programme, as well as to members of the provincial DR-TB Review Committee for their various contributions to the development of the protocol.

Author contributions. CN developed the initial draft. SA and LL provided conceptual and methodological guidance, and contributed to the further development and coherence of the manuscript. All the authors read and approved the final manuscript.

Funding. This work received funding from the University Research Committee (URC) of the University of Cape Town.

Conflicts of interest. None.

1. Moyo S, Cox HS, Hughes J, et al. Loss from treatment for drug-resistant TB: Risk factors and patient outcomes in a community-based program in Khayelitsha, South Africa. PLoS One 2015;10(3):e0118919. https://doi.org/10.1371/journal. pone.0118919

2. Evans D, Schnippel K, Govathson C, et al. Treatment initiation among persons diagnosed with drug-resistant TB in Johannesburg, South Africa. PLoS ONE 2017;12(7):e0181238. https://doi.org/10.1371/journal.pone.0181238

3. Hughes J, Osman M. Diagnosis and management of drug-resistant TB in South African adults. S Afr Med J 2014;104(12):894. https://doi.org/10.7196/SAMJ.9097

4. Churchyard GJ, Mametja LD, Mvusi L, et al. Tuberculosis control in South Africa: Successes, challenges and recommendations. S Afr Med J 2014;104(3 Suppl 1):S244-S248. https://doi.org/10.7196/samj.7689

5. Andrews JR, Morrow C, Walensky RP, Wood R. Integrating social contact and environmental data in evaluating TB transmission in a South African township. J Infect Dis 2014;210(4):597-603. https://doi.org/10.1093/infdis/jiu138

6. Verver S, Warren RM, Munch Z, et al. Proportion of TB transmission that takes place in households in a high-incidence area. Lancet 2004;363(9404):212-214. https://doi.org/10.1016/S0140-6736(03)15332-9

7. Bayer R, Dupuis L. Tuberculosis, public health, and civil liberties. Ann Rev Public Health 1995;16:307-326. https://doi.org/10.1146/annurev.pu.16.050195.001515

8. Beggs CB, Noakes CJ, Sleigh PA, Fletcher LA, Siddiqi K. The transmission of TB in confined spaces: An analytical review of alternative epidemiological models. Int J Tuberc Lung Dis 2003;7(11):1015-1026.

9. Taylor JG, Yates TA, Mthethwa M, Tanser F, Abubakar I, Altamirano H. Measuring ventilation and modelling $M$. tuberculosis transmission in indoor congregate settings, rural KwaZulu-Natal. Int J Tuberc Lung Dis 2016;20(9):1155-1161. https://doi.org/10.5588/ijtld.16.0085

10. Zonana H. Warning third parties at risk of AIDS: APA's policy is a reasonable approach. Hosp Commun Psychiatr 1989;40(2):162-164.

11. World Health Organization. Guidance on ethics of TB prevention, care and control. WHO Library Cataloguing-in-Publication Data. Geneva: WHO, 2010. http://apps.who.int/iris/bitstream/10665/44452/1/9789241500531_eng.pdf (accessed 21 November 2017)

12. Ferris LE, Barkun H, Carlisle J, Hoffman B, Katz C, Silverman M. Defining the physician's duty to warn: Consensus statement of Ontario's Medical Expert Panel on Duty to Inform. CMAJ 1998;158(11):1473-1479.

13. Tremayne-Lloyd T. Medicolegal file. Right to confidentiality versus duty to disclose. Can Fam Physician 2001;47:495-496.

14. Odunsi B. Should caregivers be compelled to disclose patients' HIV infection to the patients' sex partners without consent? Stud Family Plan 2007;38(4):297-306. https://doi.org/10.1111/j.1728-4465.2007.00142.x

15. Minister of Health of the Province of the Western Cape $v$ Goliath and Others (13741/07) (2008) ZAWCHC 41; 2009 (2) SA 248 (C) (28 July 2008). http://www. saflii.org/za/cases/ZAWCHC/2008/41.pdf (accessed 2 October 2019).

16. Constitution of the Republic of South Africa. 1996. https://www.refworld.org/ docid/3ae6b5de4.html (accessed 19 June 2020).

17. Republic of South Africa. National Health Act (Act 61 of 2003). http://www.info. gov.za/gazette/acts/2003/a61-03.pdf (accessed 19 June 2020).

18. Health Professions Council of South Africa. Guidelines for Good Practice in the Health Care Professions. https://www.hpcsa.co.za/Uploads/Professional Practice/Ethics_Booklet.pdf (accessed 19 June 2020).

19. Adams S, Morar R, Kolbe-Alexander T, Jeebhay M. Occupational health challenges facing the Department of Health. In: Padarath A, English R, editors. South African Health Review 2012/13. Durban: Health Systems Trust, 2013:103-122.

20. UN General Assembly. International Covenant on Economic, Social and Cultural Rights. 16 December 1966. United Nations Treaty Series, vol. 993:33. http://www. refworld.org/docid/3ae6b36c0.html (accessed 8 September 2018). 
21. UN General Assembly. International Covenant on Civil and Political Rights. 16 December 1966. United Nations Treaty Series, vol. 999:171. http://www.refworld. org/docid/3ae6b3aa0.html (accessed 8 September 2018).

22. South Africa. Occupational Health and Safety Act No. 85 of 1993. http://www. info.gov.za/acts/1993/a85-93.pdf (accessed 19 June 2020).

23. Republic of South Africa. Basic Conditions of Employment Act (Act 75 of 1997) https://www.gov.za/sites/default/files/gcis_document/201409/a75-97.pdf (accessed 19 June 2020)

24. South Africa. Labour Relations Act No. 66 of 1995. http://www.info.gov.za/ acts/1995/a66-95.pdf (accessed 19 June 2020).

25. Republic of South Africa. Compensation for Occupational Injuries and Diseases Act (Act 130 of 1993). http://www.info.gov.za/acts/1993/a130-93.pdf (accessed 19 June 2020).

26. Department of Labour, South Africa. Unemployment Insurance Act, 2001 (Act 63 of 2001). https://www.gov.za/sites/default/files/gcis_document/201912/42821 rg110 01gon1421.pdf (accessed 19 June 2020).

27. South Africa. Social Assistance Act (Act 13 of 2004). https://www.gov.za/sites/ default/files/gcis_document/201409/a13-040.pdf (accessed 19 June 2020).

28. City of Cape Town. Environmental Health By-law (2003). http://resource. capetown.gov.za/documentcentre/Documents/Bylaws\%20and\%20policies/ Environmental\%20Health\%20By-law.pdf (accessed 19 June 2020).

29. Kendall EA, Azman AS, Cobelens FG, Dowdy DW. MDR-TB treatment as prevention: The projected population-level impact of expanded treatment fo multidrug-resistant TB. PLoS One 2017;12(3):e0172748. https://doi.org/10.1371/ journal.pone.0172748
30. Appelbaum PS. Tarasoff and the clinician: Problems in fulfilling the duty to protect. Am J Psychiatr 1985;142(4):425-429.

31. United Nations Economic and Social Council. The Siracusa Principles on the limitations and derogation provisions in the International Covenant on Civil and Political Rights. UN Doc. E/CN.4/1985/4, Annex.1985 16 April 2016. http://www. refworld.org/docid/4672bc122.html (accessed 11 April 2019).

32. Chaimowitz GA, Glancy GD, Blackburn J. The duty to warn and protect impact on practice. Can J Psychiatr 2000;45(10):899-904. https://doi. org/10.1177/070674370004501004

33. Mor Z, Chemtob D, Hildesheimer GM, Leventhal A. AIDS and the right to privacy Harefuah 2007;146(3):200-205/245-246.

34. London L. Confinement for extensively drug-resistant TB: Balancing protection of health systems, individual rights and the public's health. Int J Tuberculosis Lung Dis 2009;13(10):1200-1209.

35. London L. Dual loyalties and the ethical and human rights obligations of occupational health professionals. Am J Industr Med 2005;47(4):322-332. https:// doi.org/10.1002/ajim.20148

Accepted 18 November 2019 